\title{
COORDINATION OF GEOSPATIAL ACTIVITIES FOR SUPPORTING PLANNING OF RESIDENTIAL INFRASTRUCTURE DELIVERY
}

\author{
Mohammed Alqarni, Ph.D. \\ GIS Department \\ Riyadh Municipality, Riyadh, Saudi Arabia
}

\begin{abstract}
The development of geospatial technologies has attracted the interest of sectors responsible for urban development projects due to their ability to manage and analyse spatial data that provides support for decision makers. In Saudi Arabia, geospatial activities have developed in the majority of agencies responsible for urban infrastructure provision and they have continued to adopt and further exploit the potential of these technologies. This has played a major role in disseminating geospatial technologies and contributed to the development of spatial data. However, the use of these technologies has not yet reached the desired level and is often fraught with challenges. This study focuses on the nature of the coordination of geospatial activities within agencies that have responsibilities for the planning and delivery of residential infrastructure in Riyadh City. It aims to explore the actual practices and highlight critical issues facing unification of efforts, with the aim of improving spatial data access, integration, and interoperability to support the relevant decision-making. The results show that the coordination of geospatial activities between the different agencies is still limited. They reveal the need for an organisational framework that supports the alignment of these activities among different agencies to minimise duplication of efforts. The study develops strategies for addressing the current situation and provides recommendations based on the results.
\end{abstract}

Keywords - Geospatial Technology, Coordination, Residential Infrastructure, Delivery, Planning

\section{INTRODUCTION}

During the past five decades, Riyadh City has witnessed rapid urban growth associated with many demographic, economic and social variables. This growth has largely contributed to the accelerated pace in the establishment of residential areas in an unstructured pattern, in order to meet the needs of population growth. This dramatic shift in the spread of residential areas has placed enormous pressure on infrastructure. Despite improvements in urban management and planning, the city continues to have problems with imbalance in the distribution of infrastructure and the increase in its delivery costs, coupled with difficulties in coordination between responsible agencies, lack of data, and the inaccuracy of available information to deal with such issues (Mubarak, 2004; Aina, 2017)

The escalation of spending for the delivery of public services and utilities has created a need for innovative solutions to facilitate the planning and management processes and decision-making needed to meet the requirements of residents. The realisation that the majority of data related to infrastructure delivery is spatially associated, has prompted many of the agencies to use geospatial technologies to develop the performance of their tasks. The government support to promote the implementation of these technologies has contributed to their wide development in the various sectors. As a consequence, several government and private sector agencies concerned with residential infrastructure delivery have come to depend on their large-scale use, and they are advancing rapidly. However, these agencies often implement geospatial activities independently. As such, the development of geospatial activities has not resulted in the desired expectations, which has reduced the benefits of their use to support tasks related to planning for infrastructure delivery. These issues will be investigated in this study.

\section{BACKGROUND TO STUDY}

Rapid urban growth is considered a key concern for cities' urban infrastructure providers. It is a complicated process, often resulting from a combination of economic, political, environmental, demographic, cultural and social transformations. These transformations help influence the ability of urban areas to meet residents' needs for urban infrastructure and services. Although patterns of this growth vary from one urban area to another, it often results in the expansion of residential areas.

Under these circumstances, spatial information is an important resource for undertaking urban planning and development activities (Singh and Kumar, 2012). It is also considered a necessary means to help achieve successful practice for the planning and management of urban 


\section{International Journal of Engineering Applied Sciences and Technology, 2019 Vol. 4, Issue 4, ISSN No. 2455-2143, Pages 336-344 \\ Published Online August 2019 in IJEAST (http://www.ijeast.com)}

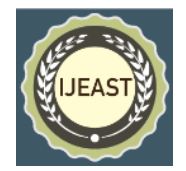

infrastructure (Coutinho-Rodrigues et al. 2011). Given the vast development of technology over the last few decades, geospatial technologies have opened a new vista to generate, collect and analyse spatial data in a beneficial way.

A review of the literature on the use of geospatial technology tools in urban areas reveals new opportunities to improve the planning, managing and delivery of urban infrastructure, along with providing many possibilities that support the decision-making (Lewis and Ogra, 2010; Pfeffer et al. 2015). Currently, the use of these technologies has become more widespread in addressing many issues facing urban areas, which goes beyond the mere function of mapping and spatial data generation (Jensen et al., 2005; Rinner, Hanzl, 2007; Lin, 2013; Baud et al., 2011,2015). They are characterised as being able to understand location-based issues by adding accurate and reliable locations to existing information and provide effective methods of organising this information from different sources (Steudler and Rajabifard, 2012). Geospatial technologies also have a set of choices to gather and control the data access and its use. Furthermore, these applications are often employed in an integrated fashion, for example combining existing data from fieldwork, data from remote sensing images as well as GPS data with webbased databases, in a single uses environment. Therefore, they became an important tool, introducing new ways for facilitating and supporting decision-making to ensure coordinated delivery of urban infrastructure.

With the increased availability of the Internet, web-based geospatial technological development has contributed to allowing various applications and mapping software to access the data and support infrastructure planning and delivery (Aditya, 2010). The review of literature pointed to a number of benefits for web-based geospatial tools in the planning process, including the ability to make data available before, during and after the planning process, in addition to enhancing participation and expressing the needs and concerns for improving decisions related to infrastructure planning processes. A new way to support e-governance initiatives in its tasks related to service delivery has also opened up (Thurston et al., 2003). Furthermore, a number of studies have argued that the tools of this technology play a significant part in the move to make cities smart, due to their ability to facilitate the operations of managing infrastructure projects and making their components and services more intelligent, interconnected and efficient (Al-Hader et al., 2009,2009; Li et al., 2015).

More specifically, geospatial tools provide the means to generate the information needed and employ them to achieve a better understanding of the spatial distribution of infrastructure (Ayeni, 1997; Rahman et al., 2011). Patnaik (2013) indicates that these technologies can help decision makers utilise spatial data to design polices related to the needs of infrastructure provision resulting from urban expansion, and to support the ability to predict expansion along with evaluating services and utilities spatially distributed. They can also be used to identify the extent of the adequacy and coverage of existing infrastructure and services (Nedovic-Budic, 2010). Thus, they are important tools for achieving equality in distribution of these services and facilities within residential neighbourhoods and disadvantaged areas. Furthermore, geospatial tools provide an insight into finding more effective ways for delivering urban infrastructure in terms of costs and the possibility of different alternatives for implementation (Coutinho-Rodrigues et al., 2011). Geospatial tools also provide the information needed for testing infrastructure network extensions, which assist in making decisions during the planning process and estimating the expected cost involved in development prior to the implementation (Biermann, 2003; Gebetsroither-Geringer and Loibl, 2015).

In Saudi Arabia, as is the case in many countries, the implementation of geospatial technology has gained momentum in several government and private sector agencies concerned with residential infrastructure delivery. The governmental support in this field has had a major role in disseminating those technologies (Alshehri, 2007). The establishment of the National Committee for Geographic Information Systems (NCGIS) by the Council of Ministers, the highest regulatory authority in the country, was one of the most prominent of these efforts towards ensuring the coordination of efforts between the various agencies. It was also a positive step towards introducing fundamental changes and leading the geospatial technology activities to coordinate a more organised situation. Also, the agencies producing spatial data played a similar role in their broad dissemination. These agencies include the General Commission for Survey (GCS), Ministry of Municipal and Rural Affairs (MOMRA), General Authority for Statistics (GAS), Saudi Geological Survey (SGS), Saudi Post (SP), King Abdulaziz City for Science and Technology (KACST) and the High Commission for the Development of Riyadh (HCDR) (Algarni, 2006).

Over the past years, many efforts have emerged to employ geospatial tools in agencies responsible for residential infrastructure delivery in the city of Riyadh. For example, Riyadh Municipality is currently working on creating and developing many applications based on geospatial technologies to support facilitation of the tasks and functions of the Municipality's various departments. Such geospatial applications cover a wide range of topics, including city planning, land division system, cartography, utility management, permits, reporting system, studies and designs and interactive maps. The General Directorate of Civil Defence (GDCD) is another example, where this technology is employed as a means of supporting daily tasks. They created a specialised administration for linking maps with spatial data to enable civil defence teams to deal with communication of accidents swiftly and effectively. Moreover, it produced a number of spatial applications for smartphones which allowed citizens to take advantage of them for the reporting of accidents. A "Makany" system is an example of geospatial uses in those sectors, launched by the General Directorate of Education (GDE) to serve as a guide for locating schools. The system provides information on all educational facilities in all neighbourhoods according to their spatial locations. Moreover, 


\section{International Journal of Engineering Applied Sciences and Technology, 2019 Vol. 4, Issue 4, ISSN No. 2455-2143, Pages 336-344 \\ Published Online August 2019 in IJEAST (http://www.ijeast.com)}

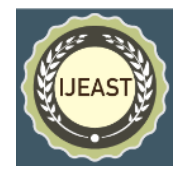

the Saudi Post worked on the implementation of the national address project in 2010, providing spatial data for systems and applications developers via its website, with the aim of facilitating the use of maps and spatial data.

In the field of physical infrastructure services, the Saudi Telecom Company (STC) also adopted an ambitious plan to build a comprehensive spatial database to expand its services, and a number of applications were designed in the fields of planning and provision of information, business development and customer service, as well as maintenance activities (Abdulaal, 2005). Similarly, the Saudi Electricity Company (SEC) created a centre for GIS and developed many applications that serve the company in the field of planning, as well as other services related to the reporting of emergencies and maintenance in addition to the management of field teams (Albogami, 2006). The National Water Company (NWC) also adopted the development of systems based on geospatial technologies in order to manage water and sanitation systems, and to enhance their customer services.

Despite efforts to support the development, implementation and use of geospatial technologies, absence of strategies and legislation that support cooperation and integration did not keep pace with their development (Alshehri, 2007). This has also created an unintegrated environment making compatibility between the various agencies difficult to achieve. As a result, an overlap in efforts, duplication of implementation because of the multiplicity of government agencies, and the disparity in their assigned tasks, and the ways of using these technologies have continued and have become more complicated. In addition, different versions of spatial data emerged, issued in accordance with different standards and specifications established by each agency without reference to local or international standards which has had a negative effect on its quality, accuracy and possibility of exchange. This in turn contributed to an increase in the financial wastage associated with implementation and minimisation of benefits that could be provided. So far, geospatial activities are implemented independently within different sectors (Al-Ankary, 1991; Kubbara, 2002; Algarni, 2006; Alshehri, 2007; Alsultan and Rahman, 2015). Along with this, the cooperation and coordination in geospatial activities is still in the early stages (Alsultan and Abdulrahman, 2015). Meanwhile, the issues of repetition of projects among different agencies, accuracy and standards of spatial data are continuing.

This study examines the factors behind the lack of coordination in using geospatial technology at agencies concerned with delivery of residential infrastructure, and concludes with strategies and recommendations for decisionmakers and urban and infrastructure planners when considering their implementation.

\section{METHODOLOGY}

This study mainly focuses on addressing issues related to coordination in the use of geospatial technologies between the agencies responsible for residential infrastructure delivery. The main question of this study is, what are the reasons that limit the coordination and how are they being addressed? This calls for using a method that facilitates the elicitation of opinions from responsible experienced persons who represent all relevant agencies. Therefore, the Delphi method was considered appropriate for investigation to reach a consensus about the strategies that can be employed to improve the coordination in the use of these technologies to support decision-making in the planning and delivery of residential infrastructure. This method has been used in many different disciplines as an approach that enables a group of individuals to deal with extremely complex problems (Mukherjee et al. 2015). It can be defined as a method for collecting and exchanging opinions, through a series of consultations among a group of experts, to reach a reliable consensus or judgement on a particular topic (Williams and Webb, 1994; Guzys et al. 2015). In general, the Delphi method is characterised by anonymity of participants involved in the study, controlled feedback and statistical response (Linstone and Turroff, 1975, 2002). Using the Delphi method, the selected experts normally answer questions in two or more rounds, where a summary of the results from the previous rounds is communicated and evaluated to reach consensus.

In the current study, the expert panel members were selected based on their positions through purposive sampling. To guarantee diversity of experience, the sample consisted of decision-makers and department managers who are responsible for geospatial technologies. They were selected from 13 agencies representing all residential infrastructure providers and other governmental agencies that support working with these technologies. The study was conducted in three iterative rounds in which qualitative data were collected in the first round and quantitative data in the second and third rounds. 20 experts participated in the first round, although only 18 responded in the second and third round.

The researcher used both qualitative and quantitative research methods to obtain a better understanding. The first Delphi round was conducted by face-to-face interviews. Questions asked to experts were open questions to generate responses on issues they considered key in affecting the coordination of geospatial technology activities in the agencies responsible for planning the delivery of residential infrastructure, along with the reasons causing these issues and how they could be addressed. The interview data collected was analysed using thematic analysis. During the analysis phase, the most commonly recurring themes were identified, and these were used to produce items for the subsequent rounds. The second and third rounds of the study were carried out using questionnaires. These were sent to the participants via an email in electronic format, and in hard copy for some expert panel members according to their personal preference. In the second round, experts were asked to rate their level of agreement with 13 items, identified in the first round using a five-point Likert scale ranging from 1 (Not Important) to 5 (Very Important). 


\section{International Journal of Engineering Applied Sciences and Technology, 2019 Vol. 4, Issue 4, ISSN No. 2455-2143, Pages 336-344 \\ Published Online August 2019 in IJEAST (http://www.ijeast.com)}

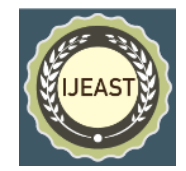

Meanwhile, in the third round, each expert received a questionnaire that included the items and ratings summarised in the second round. The researcher again asked the experts to rerate their answers for each item and provide further comments. The analysis of the data obtained in these rounds was based on measures of central tendency (mean) to measure the responses to each item, and interquartile range (IQR), used to determine the level of consensus among experts (Hsu and Sandford, 2007). In this research, the consensus criterion was an IQR of 0 of 1 (Heiko, 2012). Consensus was reached for 12 of the 13 items after the second round, while in the third round, consensus was reached for the same items and, consequently, it was decided that no further rounds were required.

\section{DATA ANALYSIS}

\section{A. The first round -}

Before the first round, the interview questions were formulated after a review of the relevant existing literature on the organisation and coordination of geospatial technology. The main objective of this round was to analyse the data collected from the experts about the reasons behind the low levels of coordination of geospatial technology activities between the agencies, and how they can be addressed in order to develop themes for the following rounds.

In the beginning, experts were asked about the level of coordination that exists between those agencies, and what improvements were needed. The weakness in the level of coordination was noted throughout their answers, although there is a growth in the use of geospatial tools in some of the agencies concerned with residential infrastructure delivery. In fact, the adoption and use of such technologies in daily work activities and keeping pace with its developments requires a willingness to accept organisational and technological changes, which in itself poses a challenge, especially in bureaucratic agencies. Although the nature of functions related to residential infrastructure delivery are very similar, the integration and coordination of geospatial technology activities used is difficult to achieve in practice due to varying organisational structures and the absence of relevant strategies. Therefore, the individual implementation of these technologies was the salient feature in such circumstances.

The effect of this is evident in the level of disparity in the adoption and use of geospatial technology tools from one organisation to another, as exploitation of these technologies has not been at the same pace. It was observed during interviews with experts that a number of agencies continue to use a limited number of these tools in a traditional way, while others are using modern and sophisticated tools. They indicated that one of the reasons for this disparity is that a number of organisations focus fully on the implementation of this technology primarily at the level of the central ministries and in isolation from its agencies at city level. This was evidenced by the reference from a number of experts regarding the limited support provided, by some of the central organisations to their agencies at city level, in the adoption and use of these tools within tasks related to residential infrastructure delivery. This, in turn, reduced the attention given by some of the agencies for developing the use of geospatial technologies, which increased the difficulty in finding solutions for coordination and integration between them. In contrast, some experts voiced that a number of agencies seek to optimise the potential benefits offered by these technologies and use the tools, which allows them to develop a number of applications to improve the performance of tasks related to the delivery of services, in both planning and implementation.

On the other hand, the majority of experts believe that the lack of coordination among different agencies resulted from the expansion of geospatial technology use. They also consider that the establishment of the NCGIS did not introduce any fundamental changes in organising, coordinating and directing the geospatial technology activities even though its membership includes a wide range of representatives from various sectors. In the same context, some experts have alluded to initiatives carried out at local level by the Arriyadh Development Authority (ADA), which the NCGIS did not take part in, to coordinate geospatial technologies activities among the different agencies. This initiative did not last long, where a greater support of legislative authorities and institutionalisation of the processes in these agencies was needed so as not to conflict with the reality of organisational complexity. Nevertheless, they referred that there is a limited number of agencies who coordinate with each other. This is attributed to the absence of mechanisms that determine the way they should coordinate the activities of different technologies to achieve the benefits behind their implementation, and thus, the majority of the current coordination processes lack formal frameworks. In other words, these coordination processes lack the policies, agreements, rules and procedures and even common guidelines that define the mechanisms and channels of coordination. Interestingly, the ongoing coordination between some agencies is still bureaucratic, and executed via the traditional methods through official request letters. The interviews also show that most areas of coordination are largely limited to such aspects relating to the exchange of spatial data without other aspects associated with the implementation of those technologies. In the same context, a number of experts believed that the absence of coordination mechanisms led to the unwillingness on the part of some agencies to cooperate in activities related to those technologies. The reason for this could be due to the current methods of coordination that may not correspond with the agencies' priorities or attitudes.

The interviews further revealed that the absence of leadership with the ability to coordinate the implementation of geospatial technology activities is one of the key reasons that limit the possibility of integration, and thus, cannot be employed to support participation in decision-making related to addressing issues regarding residential infrastructure delivery. A number of experts raised this issue and they noted the importance of having a body at local level responsible for leading the coordination of geospatial technology-related activities, and improving the arrangements for coordination. 


\section{B. The second and third round -}

The questionnaire for the second round was composed based on the results of the data analysis from the first round, along with a review of the relevant literature. It consisted of a list of strategies that were developed to address the issues raised with the aim of obtaining expert opinions regarding the importance of each strategy. In addition, they were asked to express their views and present suggestions, based on their own experience. The third round was conducted in the same manner as the second round to achieve further consensus and bridge the gap between the differences in the views obtained. In this round, the strategies, along with rating a summary of the responses were presented to enable the experts to consider the replies given, and a review of their assessment to reach a final consensus and a common agreement on the final strategies.

Responses from the first round indicated a number of themes have contributed to the difficulty of coordinating the utilisation of geospatial technologies in the agencies that provide residential infrastructure. They showed that variations in the organisational context of these agencies have played a critical role in affecting the exploitation of implementing these technologies in order to improve coordination of residential infrastructure delivery processes. This, in turn, led to a limitation in the benefits of utilisation compared with their widespread diffusion.

The absence of national strategies and guidelines for geospatial information and technology were issues that affected the successful implementation of these technologies. These issues played a part in the duplication of efforts, financial waste, doubled implementation costs, as well as limiting the cooperation and coordination of work between different agencies in this field. Therefore, it can be stated that the absence of institutional organisation in geospatial implementation clearly hampered the integration of their activities and the potential to offer the required support in making decisions. This, in turn, urged many agencies to focus on enhancing their policies towards the development of using these technological tools independently.

The availability of leadership to coordinate geospatial activities between agencies, through a collaborative approach aiming to unify various efforts, is prerequisite for enhancing coordination. This will also support the exploitation of the opportunities offered by these technologies and will assist agencies with decision-making processes. The results of the experts' answers endorsed such an approach as there was consensus regarding the importance of the presence of a responsible and effective party to take the lead in organising and directing all activities related to their use.

Such agreement may serve as a good indication of the desire of the agencies to coordinate with each other, which will reflect positively on the employment of these technologies to address issues related to the delivery of services. In spite of this, there was, however, a lack of consensus identifying the agency most capable of leading these activities. This creates difficulty in coordinating the implementation process and presents challenges that have an effect on achieving the benefits and exploiting available geospatial tools within the agencies.

This finding reflects the absence of clear strategies and appropriate policies concerning the organisation of geospatial activities and can be attributed to the centralised nature of the administration of government agencies, where as yet, no agency possesses the authority empowered to lead such activities. This finding also supports the opinions, communicated in the first round, regarding the limited role of the NCGIS in developing related national policies. In addition, it reflects the confined efforts of the NCGIS in coordinating tasks related to geospatial data activities with central ministries without having a clear association and comprehensive coordination with other agencies, whether representing the public or private sector at local level.

Another justification can be that the contributions made by the e-Government programme (Yesser), in support of the implementation of e-Government initiatives and improved ICT infrastructure in government agencies, were at local level. Furthermore, the link between agencies responsible for service delivery with agencies that have the power to direct urban development in the city, whether legislative such as the ADA, or executive such as Riyadh municipality, may also be the motive behind the experts' tendency toward selecting those agencies to carry out such responsibilities.

However, there was a consensus regarding a number of organisational and supervisory tasks, to be carried out by a directing agency to enhance coordination of efforts and the development of growing uses of these technologies (see Table 1).

Table -1 Average rating of the important level of responsibilities for the agency responsible for organising and directing geospatial technologies activities

\begin{tabular}{|c|l|c|c|}
\hline No & \multicolumn{1}{|c|}{ Item } & Mean & IQR \\
\hline 1 & $\begin{array}{l}\text { Developing joint plans and setting priorities } \\
\text { for projects related to geospatial activities. }\end{array}$ & 4.8 & 0 \\
\hline 2 & $\begin{array}{l}\text { General control and supervision of activities } \\
\text { related to geospatial technologies, especially } \\
\text { those activities that affect other relevant } \\
\text { agencies/ organisations. }\end{array}$ & 4.6 & 1 \\
\hline 3 & $\begin{array}{l}\text { Organising the adoption of the budgets for } \\
\text { all programmes and activities related to } \\
\text { geospatial technologies in all relevant } \\
\text { agencies/ organisations. }\end{array}$ & 3.6 & 1 \\
\hline 4 & $\begin{array}{l}\text { Conducting regular meetings and follow-up } \\
\text { of tasks and responsibilities related to each } \\
\text { agency/ organisation. }\end{array}$ & 4.3 & 1 \\
\hline 5 & $\begin{array}{l}\text { Coordination with other relevant } \\
\text { organisations at all levels on activities } \\
\text { related to the geospatial technology. }\end{array}$ & 4.7 & 0.75 \\
\hline
\end{tabular}

Such a consensus clearly reflects the challenges faced by the agencies as a result of a lack of efforts in organising the 


\section{International Journal of Engineering Applied Sciences and Technology, 2019 Vol. 4, Issue 4, ISSN No. 2455-2143, Pages 336-344 \\ Published Online August 2019 in IJEAST (http://www.ijeast.com)}

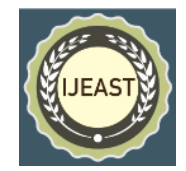

implementation of these technologies in line with their development. Therefore, it was noted that the experts concurred that the coordinating tasks related to developing joint plans and priorities as well as connecting with other relevant organisations were of high importance. This gives an indication of the desire of the experts who represent these agencies to adopt a structured approach in order to avoid duplication and inconsistency in the implementation of these technologies.

Adoption of such proposed strategies may create fundamental changes in supporting the adoption and use of geospatial technologies in processes for the delivery of services. In addition, they may lead to changes in work style and procedures, where concluding agreements among different agencies is required to ensure they are committed to performing their assigned functions and tasks. It is, therefore, important to recognise that there is a need for participation from all relevant agencies in the collective decision-making, which is often an optimal way to coordinate the actions that can be taken in line with the agencies' objectives. In this regard, experts were asked to identify the appropriate level of employees to represent the agencies concerned with services delivery when participating in activities related to developing the uses of geospatial technologies. The experts agreed that the managers responsible for geospatial technologies are considered the optimal functional level to undertake this role. However, the tasks that will be approved during coordinating meetings will not bring a positive change if there is no agency with the capacity and authority to force all related service delivery agencies to agree on participation and cooperation. The panel of experts was asked to determine the appropriate means and measures by which the various agencies could be encouraged to carry out the agreed responsibilities; however, they failed to reach a consensus. This can be attributed to the differences in the decision-making process within the relevant agencies; this makes the organisation of these activities more challenging.

As noted earlier, the implementation of geospatial technologies in agencies responsible for delivering services is carried out independently without cooperation with others, which led to disparity in levels of implementation from one agency to another. Such a disparity in implementation makes the possibility of employing these technologies in the context of improving service delivery more problematic. In this regard, the analysis showed that there was consensus among the expert panel on the importance of providing the necessary infrastructures and automated procedures related to service delivery based on geospatial technologies to support and facilitate the organisational efforts, and to achieve maximum technological benefits, which in turn can support the coordination efforts.

\section{DISCUSSION}

In light of the rapid urban growth of Riyadh city and the accompanying spread in residential areas, the need to make appropriate decisions has appeared to address many of the issues relating to the delivery of infrastructure that fits with this expansion. The development taking place in geospatial technologies, and the potential for providing both spatial and descriptive data, has encouraged many of the agencies concerned with service delivery to seek the benefits gained from the implementation of such technologies to guide the planning processes and support decision-making. However, the results from this study have shown that these developments were not sufficient to achieve optimum utilisation of their implementation. This is due to the fact that their implementation was not built on a basis that can be used for shared decision-making among the relevant agencies.

By looking at these results, one could note that the institutional and organisational issues have reflected on the integration of geospatial activities among the agencies. In fact, this explains the apparent lack of coordination and duplication of efforts, in the context of implementation, which makes the possibility of finding an organised environment to coordinate geospatial activities difficult to achieve. This is consistent with a study undertaken by Lance et al. (2009) which mentioned that the multiplicity of agencies and the complexities of government administrative arrangements creates problems coordinating geospatial activities in an effective manner. Likewise, Vancauwenberghe et al. (2014) highlighted that such organisational issues make coordination of geospatial activities difficult and complex. In the same context, it is also noted that there are governmental efforts to support diffusing geospatial technologies with the aim of improving the performance of all sectors concerned with service delivery. Nevertheless, ongoing developments in the implementation of these technologies still lacks clear institutional arrangements, effective leadership, national strategies and programmes, which enhance the cooperation, participation and facilitation of partnerships, as well as the management of geospatial information among different agencies. Reflecting on the results, it became clear that there was a lack of consensus on identifying an organisation to lead and organise these technological activities to support service delivery in residential areas.

In the context of service delivery, the organisational strategies and measures agreed by the expert panel to support the unification of efforts and coordination of technological activities can be considered a step forward in taking advantage of their implementation. However, commitment and partnership within the agencies in developing programmes, setting priorities and implementation of responsibilities remains a challenge in the absence of national strategies to organise these activities. This was evident in the results of the research, which showed lack of consensus among experts on the legislative frameworks that would oblige the agencies to implement the agreed tasks and responsibilities, as well as sharing the costs for implementing joint projects.

In the context of planning for the delivery of services, most of the information being used has a geographic or spatial component. Therefore, the exchange of spatial data can be considered a motivator to improve coordination, unify efforts and collective decision-making, where clear advantages are 


\section{International Journal of Engineering Applied Sciences and Technology, 2019 Vol. 4, Issue 4, ISSN No. 2455-2143, Pages 336-344 \\ Published Online August 2019 in IJEAST (http://www.ijeast.com)}

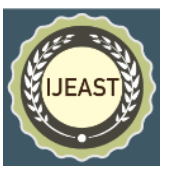

offered that encourage the agencies to be more cooperative and structured. This is consistent with a study by Jacoby et al. (2002) which demonstrated that in the absence of a geospatial strategy, the cooperation and commitment in its activities between different participants would limit the benefits accrued from their involvement. However, that may not be possible without Spatial Data Infrastructure (SDI) which provides an environment allowing for the exchange, access and use of geospatial information.

The current government policies are in fact limited in the organisation and coordination of GIS activities to establish a national SDI. This has created another challenge and a reduction in the integration opportunities for all technology related tasks and activities, which are not solely limited to GIS uses. Therefore, improving the policies and regulations to include all areas of geospatial information-related technologies are necessary to exploit the opportunities on offer.

In this context, Kok and Van Loenen (2005) state that having leadership, high level government support and improving the level of communication between stakeholders are critical to NSDI success. Therefore, activating the role of the NCGIS to carry out its responsibilities in leading and coordinating efforts related to spatial data activities, and formalising the processes that take place is imperative to address these issues. However, this requires significant government support by reconsidering its responsibilities and roles, granting administrative autonomy, authority and a budget that allows for the formation of the strategies, visions, procedures and arrangements required to develop NSDI and facilitate access to spatial data. The development of governance and institutional structures is, therefore, critical for supporting stakeholders to participate in the processes of NSDI implementation and establishing a hierarchy of structures that enables different levels of spatial data access and exchange, whether horizontally (between agencies at local level and other stakeholders) or vertically (between agencies at national and local level).

This, in turn, may provide greater opportunities to contribute to the improvement of urban governance and create frameworks that enable collective decision-making, accountability and coordination, not only on the level of service delivery but also in all different areas of development. It may also help overcome existing organisational challenges and the complexities of procedures, in addition to changing the traditional approach to the delivery of these services based on the potential offered by these technologies, as well as formalising the processes that occur.

The introduction of such changes, however, needs to address the institutional challenges as a prerequisite prior to implementing and adopting SDI. This involves addressing issues related to the centralisation of decision-making, as well as participation and coordination in the planning and implementation of activities. Improving the current institutional structures and setting clear roles and responsibilities for relevant agencies in the management of the city's development are also essential to enhance their capacity to support such activities. Furthermore, the improvement in institutional structures and governance arrangements should run concurrently with establishing legislation and the mechanisms needed for residents' participation in decision-making processes. This is in line with a study by Box (2003), which stressed the importance of shifting from centralised organisational structures and improving the institutional structures and coordination arrangements for developing the SDI.

\section{CONCLUSION}

This study presents a set of strategies that could lead to improvements in the coordination of geospatial activities to support decision-making related to the planning of residential infrastructure delivery. The results of the study show that although the obvious benefits derived from using these technologies, their implementation in the context of service delivery was, however, not built on a basis that can be used for shared decision-making among the relevant agencies. The consensus reached by experts, representing all responsible agencies working in residential services delivery, has assisted in providing a robust view of the situation. This view may contribute to broadening the benefit of the adoption and use of these technologies as tools to support more coordination and integration to provide services that meet the needs of residential areas. However, the coordination of geospatial activities between the agencies responsible for service provision relies on making improvements to implementation practices. This will ensure there are coordinated efforts, and commitment between various agencies to achieve a good level of consistency and integration of their activities. Consideration should also be given to the fact that this alone would not be sufficient without further developing the organisational aspects of decision-making related to the planning of infrastructure delivery in residential areas.

\section{ACKNOWLEDGEMENTS}

This study is a part of the $\mathrm{PhD}$ research of the first author. The author would like to express sincere thanks to all who contributed in any way to the production of this study.

\section{REFERENCE}

Abdulaal A. A. (2005). Developing Land Base Maps from Satellite Image: STC Experiences. [Unpublished manuscript].

Aditya T. (2010). Usability issues in applying participatory mapping for neighborhood infrastructure planning. Transactions in GIS, 14, (pp.119-147).

Aina Y. A. (2017). Achieving smart sustainable cities with GeoICT support: The Saudi evolving smart cities. Cities, 71, (pp. 49- 58).

Al-Ankary K. M. (1991). An incremental approach for establishing a geographical information system in a 


\section{International Journal of Engineering Applied Sciences and Technology, 2019 \\ Vol. 4, Issue 4, ISSN No. 2455-2143, Pages 336-344 \\ Published Online August 2019 in IJEAST (http://www.ijeast.com)}

developing country: Saudi Arabia. International Journal of Geographical Information System, 5(1), (pp.85- 98).

Algarni, A. (2006). Geographical Information Systems (GIS), Fundamental and operational concepts, Standards, Specifications, Design and Spatial Analysis, Obican.

Al-Hader, M., Rodzi, A., Sharif, A. R., \& Ahmad, N. (2009). SOA of smart city geospatial management. Third UKSim European Symposium on Computer Modeling and Simulation, (pp.6-10).

Al-Hader, M., Rodzi, A., Sharif, A. R., \& Ahmad, N. (2009). Smart city components architicture. International Conference on Computational Intelligence, Modelling and Simulation (pp.93-97).

Alshehri A. (2007). The extent of cooperation and duplication in projects and applications between government agencies in the field of geographic information systems. The 2nd National GIS Symposium in Saudi Arabia. Dammam, Saudi Arabia.

Alsultan S. H., and Rahman A. A. (2015). Kingdom of Saudi Arabia Geospatial Information Infrastructure-An Initial Study. The International Archives of Photogrammetry, Remote Sensing and Spatial Information Sciences, (pp.40- 95).

Ayeni B. (1997). The design of spatial decisional support systems in urban and regional planning. In Timmermans, $\mathrm{H}$. (ed.) Decision Support Systems in Urban Planning, London: E \& FN Spon.

Baud I, Pfeffer K., Scott D., and Sydenstricker J. (2011). Developing participatory 'spatial' knowledge models in metropolitan governance networks for sustainable development Literature Review. Bonn: EADI, Change2 Sustain.

Baud I., Scott D., Pfeffer K., Sydenstricker-Neto J. and Denis E. (2014). Digital and spatial knowledge management in urban governance: emerging issues in India, Brazil, South Africa, and Peru. Habitat International. 44, (pp.501- 509).

Coutinho-Rodrigues J., Simão A. and Antunes C.H., (2011). A GIS-based multicriteria spatial decision support system for planning urban infrastructures. Decision Support Systems, 51(3), (pp.720- 726).

Guzys D., Dickson-Swift V., Kenny A. and Threlkeld G. (2015). Gadamerian philosophical hermeneutics as a useful methodological framework for the Delphi technique. International Journal of Qualitative Studies on Health and Well-being, 10, 26291

Hanzl M. (2007). Information technology as a tool for public participation in urban planning: a review of experiments and potentials. Design Studies, 28, (pp.289- 307).
Heiko A., (2012). Consensus measurement in Delphi studies: review and implications for future quality assurance. Technological forecasting and social change, 79(8), (pp.15251536).

Jacoby S., Smith J., Ting L. and Williamson I. (2002). Developing a common spatial data infrastructure between State and Local Government--an Australian case study. International Journal of Geographical Information Science, 16, (pp.305-322).

Jensen R. R., Gatrell J. D. and Mclean D. D. (2005). Geospatial technologies in urban environments, Springer.

Kok B. and Van Loenen B. (2005). How to assess the success of National Spatial Data Infrastructures?. Computers, environment and urban systems, 29(6), (pp.699-717).

Kubbara F. S. (2002). Evaluation the use of geographic information systems in Saudi Arabia.

University of Dammam. [Online]. Available at: https://www.kfu.edu.sa/en/Deans/Research/Documents/1029.p df. Accessed 11th December 2015

Lewis M. P., and Ogra A. (2010). An approach of geographic information system (GIS) for good urban governance. 18th International Conference on Geoinformatics, IEEE, (pp.1-6).

Lin W. (2013). Digitizing the Dragon Head, geo-coding the urban Landscape: GIS and the transformation of China's Urban Governance. Urban Geography, 34, (pp. 901-922).

Mubarak F. A. (2004). Urban growth boundary policy and residential suburbanization: Riyadh, Saudi Arabia. Habitat international, 28, (pp.567-591).

Linstone HA., Turroff M. (1975) The Delphi method: techniques and applications. Addison-Wesley, Reading, MA

Linstone H.A. and Turoff M. (2002). General applications: introduction. The Delphi Approach: Techniques and Applications. In Turoff M, Linstone HA (eds). AddisonWesley Publishing Company Inc: Reading, MA; 71-79. [Online] Available at: https://web.njit.edu/ turoff/pubs/delphibook/delphibook.pdf. Accessed 11th June 2016.

Mukherjee N., Huge J., Sutherland W.J., McNeill J., Van Opstal,M., Dahdouh-Guebas F. and Koedam N. (2015). The Delphi technique in ecology and biological conservation: applications and guidelines. Methods in Ecology and Evolution, 6(9), (pp.1097-1109).

Patnaik S. K. (2013). Accessibility Assessment of Urban Infrastructure for Planning and Management of Urban Growth: A Case Study of North Lakhimpur Town, Assam, 
India. International Journal of Remote Sensing and GIS, 2, (pp.80-91).

Pfeffer K., Martinez J., O’Sullivan D. and Scott D. (2015). Geo-technologies for spatial knowledge: challenges for inclusive and sustainable urban development. Geographies of Urban Governance, Springer, Cham, (pp. 147-173).

Singh N., and Kumar J. (2012). Urban growth and its impact on cityscape: A geospatial analysis of Rohtak City, India. Journal of Geographic Information System, 4(01), (p.12- 19).

Steudler D., and Rajabifard A. eds. (2012). Spatially Enabled Society. International Federation of Surveyors (FIG).

Rahman A., Kumar Y., Fazal S. and Bhaskaran S. (2011). Urbanization and quality of urban environment using remote sensing and GIS techniques in East Delhi-India. Journal of Geographic Information System, 3 (1). (pp62- 84).

Thurston J., Moore J. P. and Poiker T. K. (2003). Integrated geospatial technologies: a guide to GPS, GIS, and data logging. John Wiley \& Sons.

Vancauwenberghe G., Dessers E., Crompvoets J., and Vandenbroucke D. (2014). Realizing Data Sharing: The Role of Spatial Data Infrastructures. Open Government. Springer.

Williams P. L., and Webb C. (1994). The Delphi technique: a methodological discussion. Journal of advanced nursing, 19, (pp180-186). 